\title{
A STUDY OF COHERENT RADIATION GENERATED IN AN ABLATIVE CAPILLARY DISCHARGE
}

\author{
JAKUB HÜBNeR ${ }^{a, b, *}$, PAVEL VRBA ${ }^{b}$ \\ ${ }^{a}$ Dept. of Physical Electronics, Faculty of Nuclear Science and Physical Engineering, Czech Technical University, \\ Břehová 7, 11519 Prague 1, Czech Republic \\ ${ }^{b}$ Institute of Plasma Physics, Academy of Sciences, 18200 Prague 8, Za Slovankou, Czech Republic \\ * corresponding author: bukajus@centrum.cz
}

\begin{abstract}
Feasible soft-X-ray amplification in the $\mathrm{C}^{\mathrm{VI}}$ and $\mathrm{N}^{\mathrm{VII}}$ Balmer $\alpha$ transition is investigated in a capillary discharge. The best conditions and parameters for the experimental set-up are found for an ablative capillary. The most optimistic results have shown that the gain would be greater than one, which is the condition for successful ASE (Amplified spontaneous emission) in capillary discharges. The capillary discharge evolution is modeled using the NPINCH program, employing a one-dimensional physical model based on MHD equations. The information about the capillary discharge evolution is processed in the FLY, FLYPAPER, FLYSPEC programs, enabling the population to be modeled on specific levels during capillary discharge.
\end{abstract}

KEYWORDS: capillary discharge, XUV or soft X-ray laser, plasma modeling, ablation.

\section{INTRODUCTION}

Non-stationary plasma of a fast capillary electrical discharge was studied as a potential active medium for a soft X-ray laser. Two types of experiments can be performed. The first type is capillary discharge, which is used to generate plasma in a channel filled with an initially preionized gas [1, 2, The second experiment involves plasma being created by a discharge by ionizing material ablated from capillary walls [3]. The detailed physical principle for creating the population inversion in the second type of experiment has not yet been well understood. Hence, the modified Shin experiment was simulated by our software equipment (NPINCH, FLY).

In fact, the capillary pinch dynamics is determined by many selected parameters: the capillary geometry (radius and capillary length), the substance of the capillary (alumina - $\mathrm{Al}_{2} \mathrm{O}_{3}$, bornitrid $-\mathrm{BN}$ ), the filling substance (carbon, nitrogen), the initial filling density (pressure), and the electric current time dependence. This dependence, in particular, is given by an electric circuit that is joined to the capillary.

A capillary discharge Z-pinch acting as a medium for a soft X-ray laser uses ASE, the "Amplified Spontaneous Emission" effect, and electron-collisional recombination pumping. The main variable for ASE is the gain [4, 13, and the most important goal of this paper is to understand the impact of each capillary parameter on the maximum gain value.

\section{Plasma modeling}

The capillary discharge dynamics is modeled by means of the NPINCH code [5]. An approximation of twotemperature (ion and electron), one-fluid magnetohydrodynamics is used. It is assumed that the length of the capillary is much greater than its diameter; hence the one dimensional approximation is relevant. It is also assumed that the current pulse profile is known and that the capillary is prefilled with weakly ionized gas. All the simulations presented here were obtained under the presumption of wall ablation. The plasma-wall interaction was modeled by considering the evaporated material from the wall as a cold neutral gas of high density and sufficiently high total mass [6].

\section{AN ANALYSIS OF THE MODIFIED SHIN EXPERIMENT}

An experiment performed by Hyun-Joon Shin et al. [3] investigates soft X-ray amplification of the Balmer $\alpha$ transition (for five times ionized carbon ion $\mathrm{C}^{5+}$ at the line $\lambda=18.2 \mathrm{~nm}$ ) observed in a polyethylene capillary with a $1.2 \mathrm{~mm}$ bore diameter. There the measured gain coefficient was $2.8 \mathrm{~cm}^{-1}$. The inner capillary plasma was created only by the ablation of the wall material.

In our "modified Shin experiment" it is proposed to use a different ablative substance for the capillary wall (alumina $-\mathrm{Al}_{2} \mathrm{O}_{3}$ or boron nitride - BN) externally filled by preionized carbon or gas nitrogen at various pressures.

The measured electric current [3] approximated by the damped sinus curve $I(t)=I_{0} \sin \frac{\pi t}{2 t_{1}} e^{-t / t_{2}}$, where $I_{0}=70 \mathrm{kA}, t_{1}=112.5 \mathrm{~ns}$ and $t_{2}=310 \mathrm{~ns}$, is introduced into the code. The radial-time dependencies of capillary plasma quantities such as plasma density, electron temperature etc. are evaluated. The results for an ablating capillary of $r_{0}=0.6 \mathrm{~mm}$ inner radius prefilled with carbon to an initial density $N_{0}=3 \cdot 10^{17} \mathrm{~cm}^{-3}$, and alumina wall material 


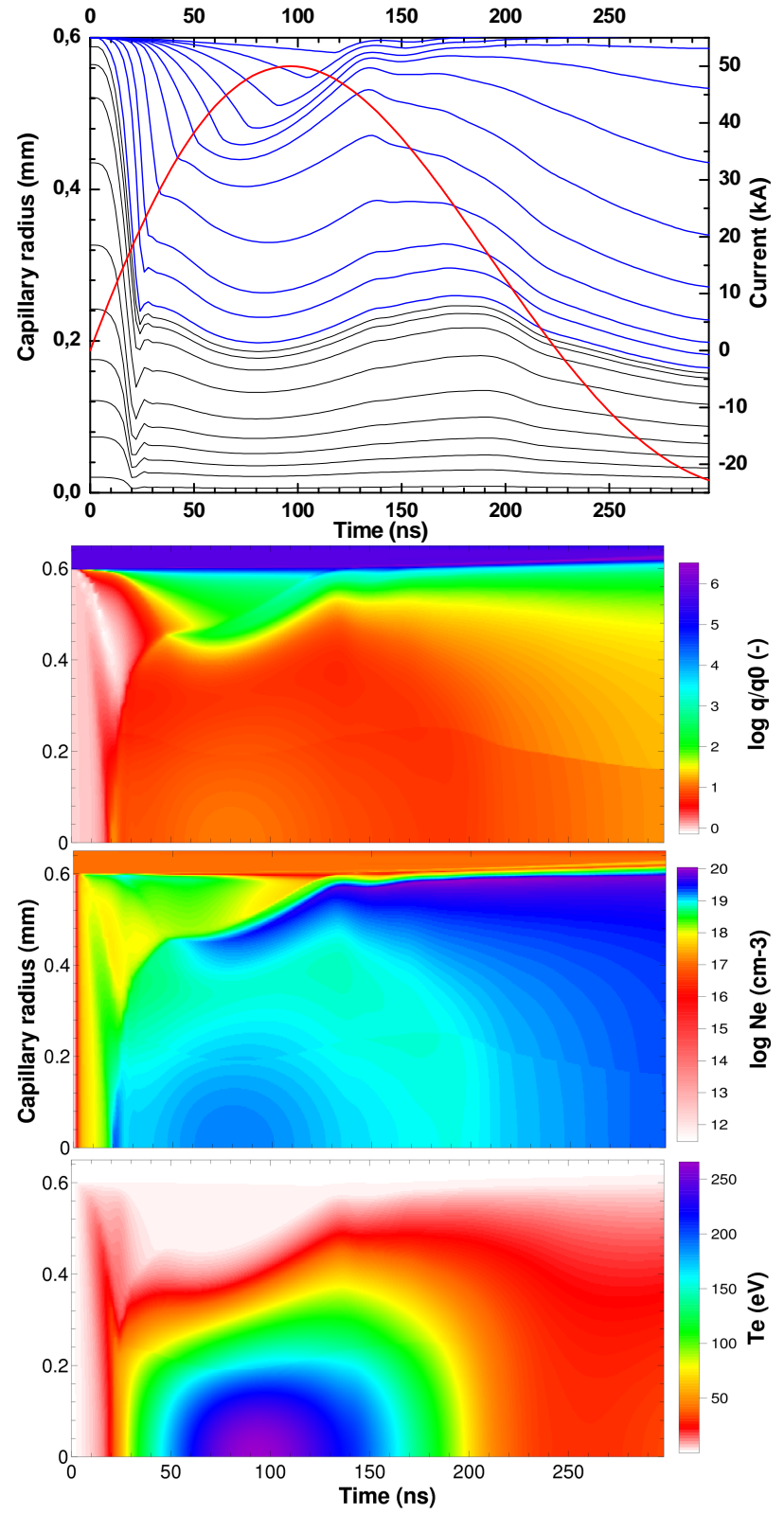

FiguRE 1. Results of computer simulations of capillary discharge dynamics for an ablating capillary of inner radius $r_{0}=0.6 \mathrm{~mm}$ prefilled with carbon to an initial density $N_{0}=3 \cdot 10^{17} \mathrm{~cm}^{-3}$, and alumina wall material $0.05 \mathrm{~mm}$ in thickness with density $\rho=3.96 \mathrm{~g} / \mathrm{cm}^{3}$. The 1st frame from the top shows radial motion of plasma mass elements. Black lines correspond to the motion of the carbon mass elements, blue lines correspond to the motion of the wall ablated material (alumina), and the red line plots the current profile $\left(I_{\max }=50 \mathrm{kA}, t_{1}=115.5 \mathrm{~ns}, t_{2}=310 \mathrm{~ns}\right)$. The $2 \mathrm{nd}$ frame shows the mass density compression ratio in $\log _{10}$ scale. The 3rd frame shows electron density in $\log _{10}$ scale and units of $\mathrm{cm}^{-3}$. The 4 th frame shows electron temperature in units of $\mathrm{eV}$.

$0.05 \mathrm{~mm}$ in thickness with density $\rho=3.96 \mathrm{~g} / \mathrm{cm}^{3}$ are shown in Figure 1. The plasma trajectories (the dependences of the radial Lagrangian coordinates of selected plasma elements on time) are depicted in the 1st frame from the top. In the 2 nd frame it can be
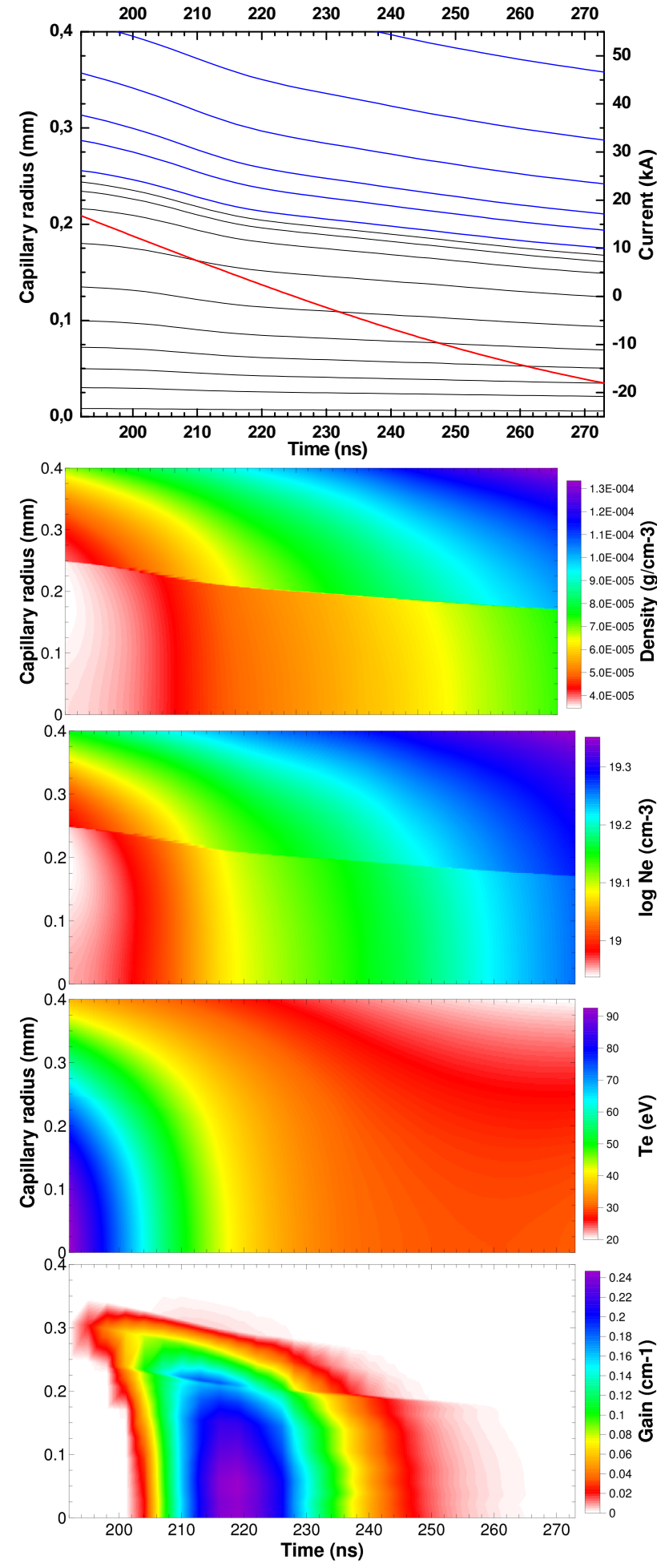

Figure 2. Zoom of Figure 1 into the area where gain is being reached. The 1st frame from the top shows radial motion of plasma mass elements. Black lines correspond to the motion of the carbon mass elements, blue lines correspond to the motion of the wall ablated material, and the red line plots a current profile. The 2 nd frame shows the mass density compression ratio in $\log _{10}$ scale. The 3 rd frame shows electron density in $\log _{10}$ scale and units of $\mathrm{cm}^{-3}$. The 4th frame shows the electron temperature in units of $\mathrm{eV}$. The 5 th frame shows the gain profile in units of $\mathrm{cm}^{-1}$. 


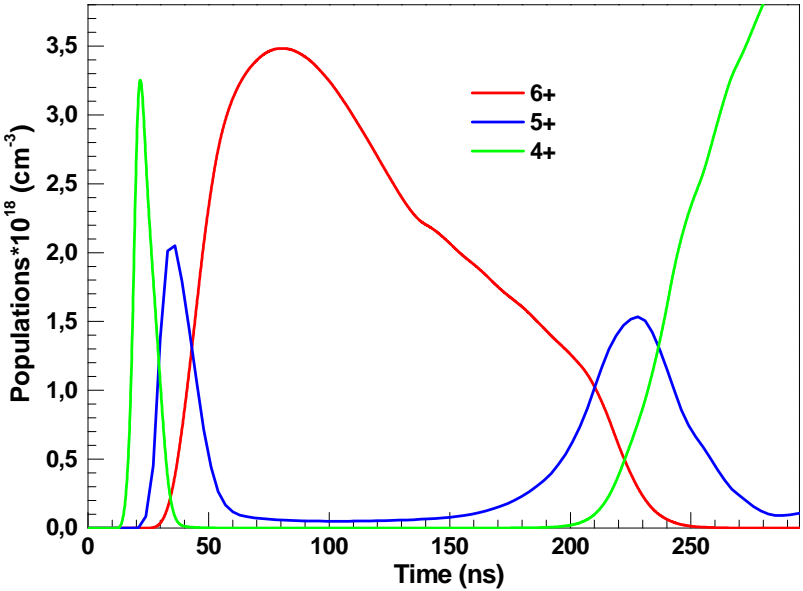

Figure 3. Showing the time history of $\mathrm{C}^{4+}, \mathrm{C}^{5+}$ and $\mathrm{C}^{6+}$ ions populations for the capillary parameters: $N_{0}=3 \cdot 10^{17} \mathrm{~cm}^{-3}, r=0.6 \mathrm{~mm}, I_{\max }=50 \mathrm{kA}, t_{1}=$ $112.5 \mathrm{~ns}, t_{2}=310 \mathrm{~ns}$, carbon inner filling, and wall material alumina.

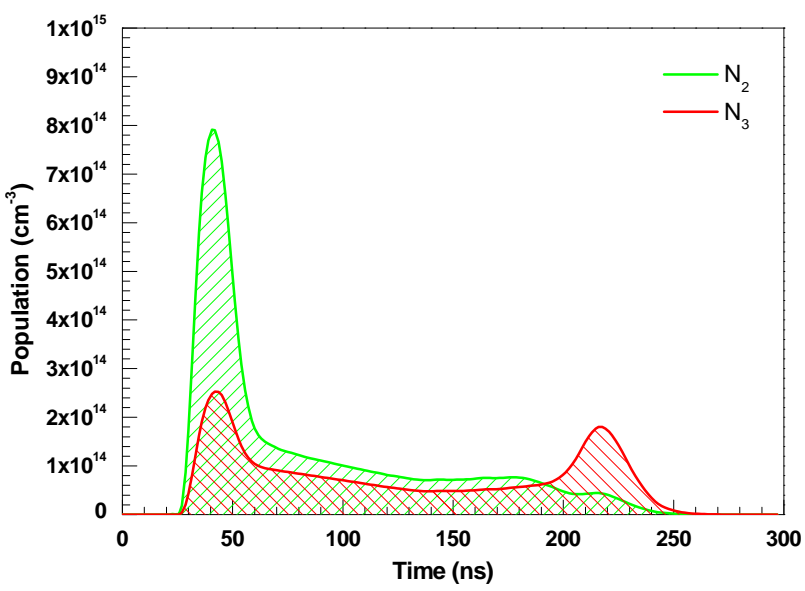

FiguRE 4. Showing the time history of populations at excited energy levels $N_{3}$ and $N_{2}$ of hydrogen-like ions $\mathrm{C}^{5+}$ for the capillary parameters: $N_{0}=3 \cdot 10^{17} \mathrm{~cm}^{-3}$, $r=0.6 \mathrm{~mm}, I_{\max }=50 \mathrm{kA}, t_{1}=112.5 \mathrm{~ns}, t_{2}=310 \mathrm{~ns}$, carbon inner filling, and wall material alumina.

seen that the first compression is achieved very early at the pinch time $t_{p 1}=20 \mathrm{~ns}$ and the compression ratio is $\log _{10} \frac{\rho\left(t_{p 1}\right)}{\rho_{0}}=1.4$. At this time, the plasma electron temperature value is $\sim 90 \mathrm{eV}$ (on the capillary axis, 4th frame) and the ion temperature is $\sim 3 \times$ higher, the plasma is non-isothermal. The second compression is achieved at $t_{p 2}=98 \mathrm{~ns}$, when the electric current reaches its maximum value (1st frame), and the compression ratio is $\log _{10} \frac{\rho\left(t_{p 2}\right)}{\rho_{0}}=1.3$ (2nd frame). The plasma becomes isothermal. The plasma electron and ion temperature values are practically the same with values of $\sim 260 \mathrm{eV}$. The plasma electron density achieves its maximum value $N_{e, \max }=1.75 \cdot 10^{19} \mathrm{~cm}^{-3}$ (3rd frame). Further time development of the carbon plasma column demonstrates enlargement of its volume and the maximum radius value is $r_{\max }=0.24 \mathrm{~mm}$ at time $t_{e 1}=190 \mathrm{~ns}$. The plasma is still quasi-isothermal $T_{e} \sim T_{i} \sim 120 \mathrm{eV}$. After the time $t>t_{e 1}$ the

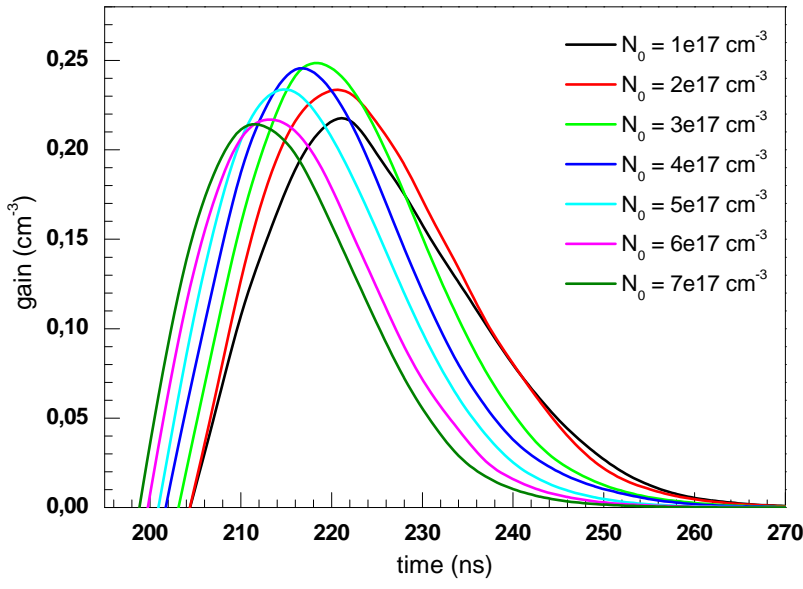

FIGURE 5. Showing the gain behavior for various initial densities $N_{0}$ in units of $\mathrm{cm}^{-3}$. For the capillary parameters: $r_{0}=0.6 \mathrm{~mm}, I_{\max }=50 \mathrm{kA}, t_{1}=112.5 \mathrm{~ns}$, $t_{2}=310 \mathrm{~ns}$, carbon inner filling, and alumina wall material.

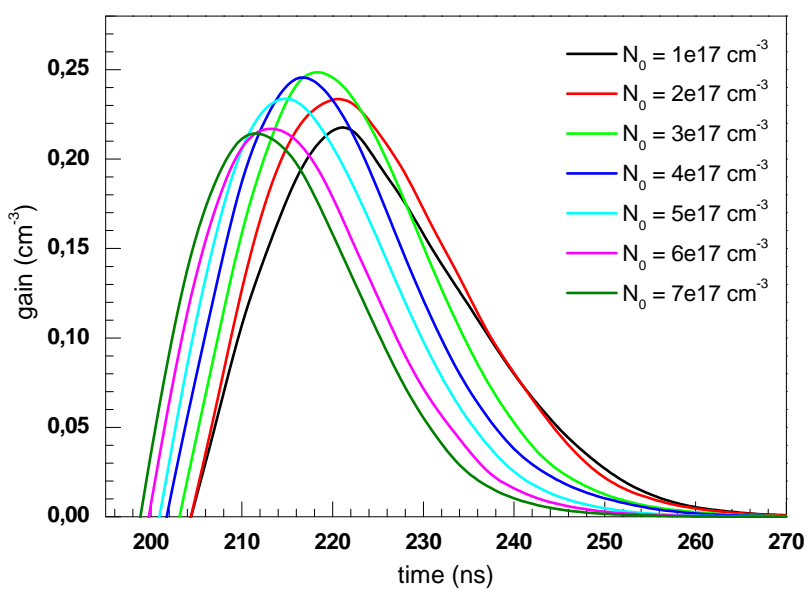

FiguRE 6. Gain behavior for various current maximum $I_{\max }=35 \mathrm{kA}, 45 \mathrm{kA}$, and $50 \mathrm{kA}$. For capillary parameters: $N_{0}=3 \cdot 10^{17} \mathrm{~cm}^{-3}, r_{0}=0.6 \mathrm{~mm}$, $t_{1}=112.5 \mathrm{~ns}$ and $t_{2}=310 \mathrm{~ns}$, carbon inner filling, and the alumina wall material.

plasma column is again compressed. During compression the plasma is exactly isothermal. We can declare that plasma occurred at the LTE state.

The kinetic behavior of plasma near the capillary axis is evaluated by the FLY code, used as a postprocessor along the plasma trajectory. The time dependences of plasma ion populations are shown in Fig. 3. Helium-like ions $\mathrm{C}^{4+}$ occurred at the very beginning (at pinch time $t_{p 1}=15 \mathrm{~ns}$ ) of plasma development. After that, the population of hydrogen-like ions $\mathrm{C}^{5+}$ culminated. The maximum value for bare $\mathrm{C}^{6+}$ is reached at the time of second compression. No inversion population between the excited state $n=2$ and 3 of hydrogen-like $\mathrm{C}^{5+}$ ions occurred at this time. The situation changes remarkably when the population of bared ions drops lower than the population of hydrogen-like ions (at time $t \sim 210 \mathrm{~ns}$ ). From this time, the hydrogen-like $\mathrm{C}^{5+}$ ions prevail 


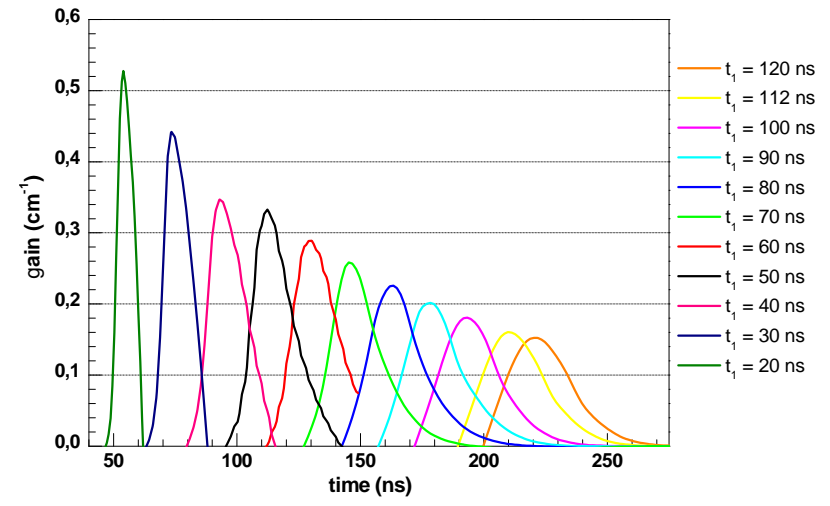

FiguRE 7. Gain behavior for various time periods $t_{1}$. For capillary parameters $N_{0}=3 \cdot 10^{17} \mathrm{~cm}^{-3}, r_{0}=$ $0.6 \mathrm{~mm}, I_{\max }=35 \mathrm{kA}, t_{2}=310 \mathrm{~ns}$, carbon inner filling, and the alumina wall material.

over both bared and helium -like $\mathrm{C}^{4+}$ ions. This is the best situation when a recombination scheme for the laser transition between an upper level $n=3$ and a lower level $n=2$ of hydrogen-like carbon ion operates (see Fig. 4). This process ends when the population of the excited hydrogen-like carbon ion in the upper level $N_{u}(n=3)$ becomes lower than the lower $N_{l}$ $(n=2)$ one. According to the Elton formulae [5, we calculated the inversion function $F=1-2.25 N_{l} / N_{u}$ and the gain $G=\sigma_{\text {stim }} N_{u} F$ (see Fig 5), where $\sigma_{\text {stim }}$ is the cross-section for stimulated emission, $\mathrm{Nu}$ is the upper state density and $\mathrm{Nl}$ is the lower state density.

\section{The ROLE OF CAPILLARY PARAMETERS}

In this section, each important capillary parameter and its influence on the capillary dynamic and on the gain in particular will be described in detail. First of all, these parameters should be defined. Three parameters relate to the shape of the current-impulse. The shape of the current impulse is defined by an electric circuit joined to a capillary. At present, most of available sources [7 [ 9 ] can be approximated by a damped sinus curve $I(t)=I_{0} \sin \frac{\pi t}{2 t_{1}} e^{-t / t_{2}}$; instead of $I_{0}$ it is better to use $I_{\max }$ (range $35-50 \mathrm{kA}$ ), which can be associated with the amount of overall energy deposited in the capillary; $t_{1}$ (range 15$120 \mathrm{~ns}$ ) is a quarter period, and $t_{2}$ (range $30-300 \mathrm{~ns}$ ) is a term for exponential decay. The fourth parameter is the initial density $N_{0}$ (range $0.5 \cdot 10^{17}$ $5 \cdot 10^{17} \mathrm{~cm}^{-3}$ ) (or pressure), and the fifth is the radius of the capillary $r_{0}$ (range $0.25-2.5 \mathrm{~mm}$ ). The length $l$ (range $2-20 \mathrm{~cm}$ ) of the capillary is much greater than the diameter, so a one-dimensional approximation is relevant. This parameter has not been dealt with in our research. In the past, some low$\mathrm{Z}$ elements were studied as possible sources of coherent radiation for recombination pumping in capillary discharges [6, 10, 11. Nitrogen and carbon were selected as the best adepts for our investigation in an ablated capillary. Capillaries are mostly

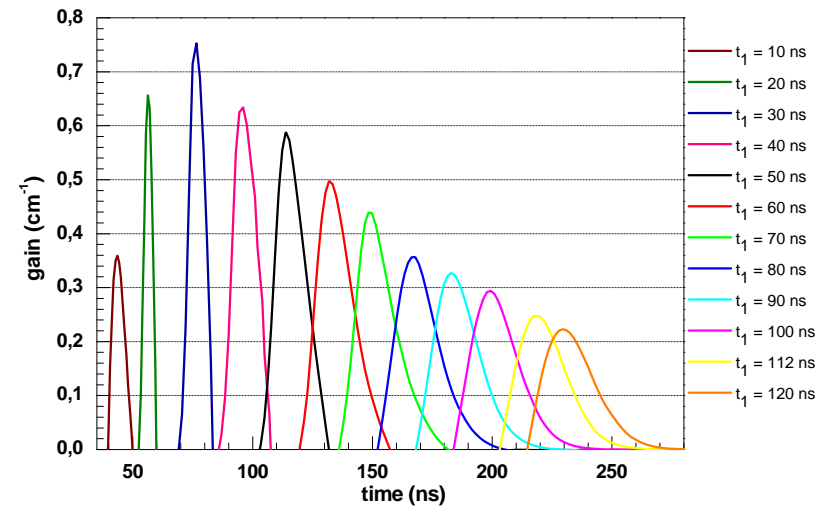

FIGURE 8. Gain behavior for various time periods $t_{1}$. For capillary parameters $N_{0}=3 \cdot 10^{17} \mathrm{~cm}^{-3}, r_{0}=$ $0.6 \mathrm{~mm}, I_{\max }=50 \mathrm{kA}, t_{2}=310 \mathrm{~ns}$, carbon inner filling, and alumina wall material.

made from alumina $\left(\mathrm{Al}_{2} \mathrm{O}_{3}\right)$ or quartz $\left(\mathrm{SiO}_{2}\right)$. Alumina was chosen as the material for the capillary, and was compared with boron nitride $(\mathrm{BN})$, which is promising new material for this model. We attempted to illustrate the influence of these parameters on the gain, and to optimize them [13]. The optimization process involves searching for the maximum gain in the five-dimensional space of these parameters. All the following figures show gain behavior only along the capillary axis, because that is where the best conditions for gain are found (Figure 2).

\subsection{Initial DENSity}

Among all the parameters, the initial density is the easiest to change in a real experiment. There always some optimal value, Figure 5, where the optimal value is $N_{0}=3 \cdot 10^{17} \mathrm{~cm}^{-3}$. The gain for the recombination of the pumping schema is mostly influenced by the behavior of the electron temperature and the ion density. The thinner the plasma is, the higher the electron temperature is at its maximum, but on the other hand the thinner the plasma is, the fewer ions at excited states it contains. The delay among the times when the gain maximum is reached for different initial densities, is due to the fact that the thinner plasma is more compressed (there are higher temperatures at the maximum) and it takes slightly more time to cool down to the electron temperatures where recombination pumping works.

This behavior is valid even if the other parameters $\left(r_{0}, I_{\max }, t_{1}, t_{2}\right)$ are changing.

\subsection{EleCtric CURRENT}

First, we investigate the influence of $I_{\max }$ on the gain. The range for $I_{\max }$ is chosen between $\operatorname{Imax}=35 \mathrm{kA}$, because there might be no ablation at the lower $I_{\max }$, and $I_{\max }=50 \mathrm{kA}$. The upper limit could definitely be even higher, but the higher $I_{\max }$ is, the more difficult it is to build such a powerful source from technical point of view. Figure 6 shows the gain behavior for 


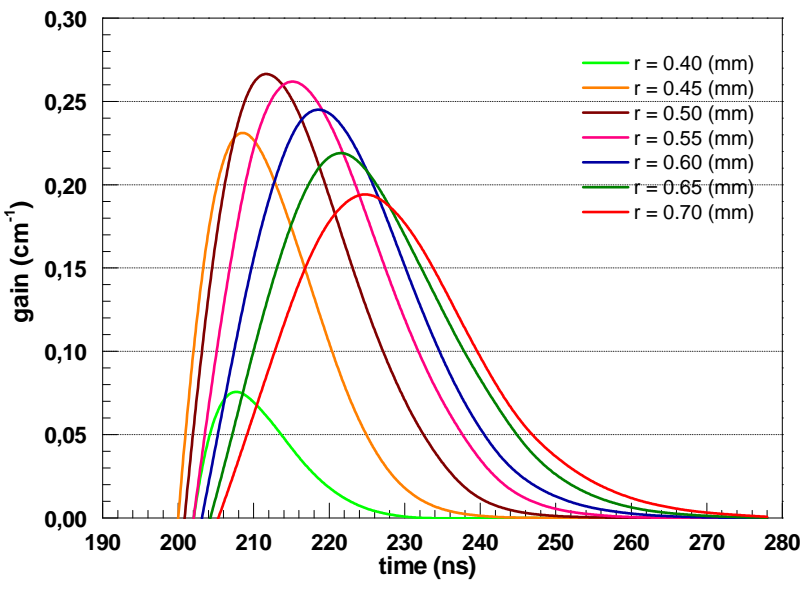

FiguRE 9. Gain behavior for various capillary inner radius $r$. For capillary parameters: $N_{0}=3 \cdot 10^{17} \mathrm{~cm}^{-3}$, $I_{\max }=50 \mathrm{kA}, t_{1}=112.5 \mathrm{~ns}$ and $t_{2}=310 \mathrm{~ns}$, carbon inner filling, and wall material alumina.

$I_{\max }=35 \mathrm{kA}, 45 \mathrm{kA}$ and $50 \mathrm{kA}$. For higher $I_{\max }$ the gain increased only slightly. The optimal $N_{0}$ was the same for all currents. The reason for the differences among the pulse shapes $\left(t_{G, \max }\right.$ - time where $G$ reached its maximum, $t_{F+}$ - time where $G$ firstly appeared and where inversion function $F$ becomes nonzero, $t_{\text {diff }}$ - difference between $t_{G \text {,max }}$ and $t_{F+}$ ) are the same as for the initial density, see above. Plasma is more compressed at higher $I_{\max }$ and it takes slightly more time to cool down.

Secondly, the influence of $t_{1}$ on the gain is investigated. The behavior of the gain for various time periods $t_{1}$ and two $I_{\max }$ parameters are shown in Figures 7 and 8, respectively. For each $I_{\max }$ there exists optimal time period $t_{1}=17.5 \mathrm{~ns}$ for $I_{\max }=35 \mathrm{kA}$ where $G_{\max } \sim 0.56 \mathrm{~cm}^{-1}$ and $t_{1}=25 \mathrm{~ns}$ for $I_{\max }=50 \mathrm{kA}$ where $G_{\max } \sim 0.78 \mathrm{~cm}^{-1}$. As $t_{1}$ becomes smaller (current pulse quicker) the profile of the gain changes, and $t_{\mathrm{diff}}$ is smaller.

\subsection{Capillary Radius}

The influence of the capillary radius is also investigated, for $I_{\max }=50 \mathrm{kA}$. Results for longer time period $t_{1}=112.5 \mathrm{~ns}$ and shorter time period $t_{2}=25 \mathrm{~ns}$ are presented in Figures 9 and 10. For both periods there is a certain optimal capillary radius. The gain is influenced only slightly with the longer time period, the optimal radius is $r_{0}=0.5 \mathrm{~mm}$ and $G_{\max } \sim 0.27 \mathrm{~cm}^{-1}$. However, the situation for the shorter time period is promising. $G_{\max }$ reached value $1.64 \mathrm{~cm}^{-1}$ for a very narrow capillary with radius $r_{0}=0.3 \mathrm{~mm}$. It should be mentioned that these results are only for initial density $N_{0}=3 \cdot 10^{17} \mathrm{~cm}^{-3}$ and are not pressure optimized.

\subsection{Optimal SET-UP FOR CARBON FILling}

Now we can take a closer look at a particular case. The best parameters for an alumina capillary filled with Carbon and $I_{\max }=50 \mathrm{kA}$ are $r_{0}=0.3 \mathrm{~mm}, t_{1}=25 \mathrm{~ns}$, $t_{2}=310 \mathrm{~ns}$. The results are shown in Figure 11. It is

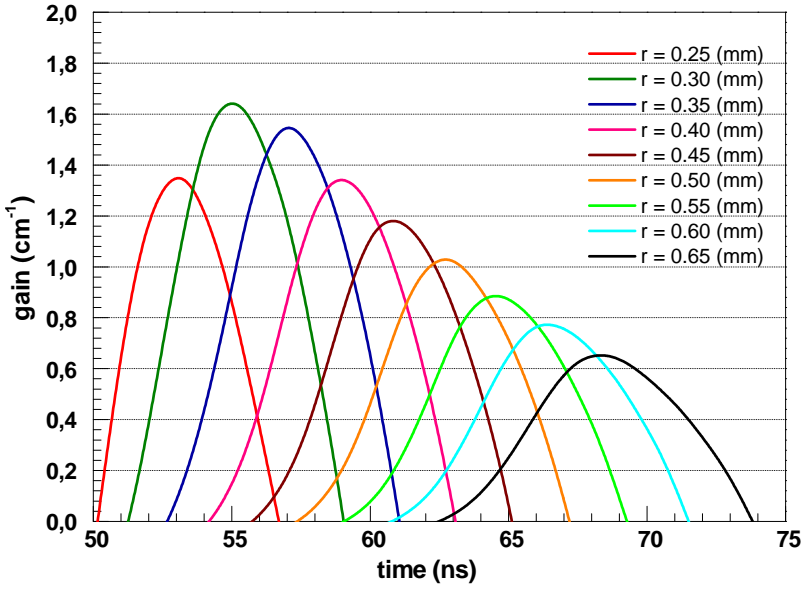

Figure 10. Gain behavior for various capillary inner radius $r$. For capillary parameters: $N_{0}=3 \cdot 10^{17} \mathrm{~cm}^{-3}$, $I_{\max }=50 \mathrm{kA}, t_{1}=25 \mathrm{~ns}$ and $t_{2}=310 \mathrm{~ns}$, carbon inner filling, and wall material alumina.

shown that a better set of parameters would increase the gain from $G_{\max }=0.25 \mathrm{~cm}^{-1}$ to $G_{\max }=1.6 \mathrm{~cm}^{-1}$. If the $r-t$ profile of the gain in Figure 11 is compared with the initial settings in Figure 1 and 2, it can be seen that the area $(r-t)$ of gain for optimal settings is smaller $r=0.1 \mathrm{~mm}$, and a possible laser pulse would be about $4 \mathrm{~ns}$ long against $r=0.2 \mathrm{~mm}$ and length of pulse about $30 \mathrm{~ns}$.

Shortening the electric current pulse leads to quicker cooling, the value of the gain increases, and the laser pulse is shortened.

Reducing the capillary radius to $R_{0}=0.3 \mathrm{~mm}$ also increases the gain. The narrower the capillary is, the more the area along the capillary axis is influenced by ablation of the capillary wall, which consequently increases the plasma density near the axis due to wall ablation.

\subsection{Optimal SET-UP FOR Nitrogen FILLING}

On the basis of recent research on non-ablated capillaries [12, it was supposed that nitrogen would also be suitable for this ablative model of pumping. At normal conditions, nitrogen is a gas, so there are none of problems with filling it into the capillary that there are with carbon filling. The results for nitrogen with the parameters discussed here $\left(N_{0}, t_{1}, r_{0}, I_{\max }\right)$ are shown in the following tables. Similar patterns were obtained for each parameter as for carbon. The results have been entered into Tables 4 to 7 . The best settings are highlighted with red color. Furthermore, all the results for nitrogen were pressure optimized and it was shown that there exists optimal $r_{0}$ only for constant $N_{0}$. The thinner the capillary is, the higher the gain that can be obtained. However, there will be some technological limits that have to be taken into consideration in a real experiment. Bornitrid as a capillary material is investigated for some cases. The results are highlighted in green. 


\begin{tabular}{ccccccc}
\hline$t_{1}(\mathrm{~ns})$ & $t_{2}(\mathrm{~ns})$ & $N_{0}\left(\mathrm{~cm}^{-3}\right)$ & $G_{\max }\left(\mathrm{cm}^{-1}\right)$ & $t_{G_{\max }}(\mathrm{ns})$ & $t_{F+}(\mathrm{ns})$ & $t_{\text {diff }}(\mathrm{ns})$ \\
\hline 12.5 & 310 & $3.0 \cdot 10^{17}$ & 0.3 & 39 & 36 & 3 \\
\hline 15 & 310 & $3.0 \cdot 10^{17}$ & 0.55 & 43.5 & 39 & 4.5 \\
\hline 17.5 & 310 & $3.0 \cdot 10^{17}$ & 0.56 & 48.8 & 43.5 & 5.3 \\
\hline 20 & 310 & $3.0 \cdot 10^{17}$ & 0.53 & 54 & 47.3 & 6.7 \\
\hline 30 & 310 & $3.0 \cdot 10^{17}$ & 0.44 & 73.5 & 64.5 & 9 \\
\hline
\end{tabular}

TABLE 1. Capillary parameters: $I_{\max }=35 \mathrm{kA}, r_{0}=0.6 \mathrm{~mm}$, carbon, alumina.

\begin{tabular}{ccccccc}
\hline$t_{1}(\mathrm{~ns})$ & $t_{2}(\mathrm{~ns})$ & $N_{0}\left(\mathrm{~cm}^{-3}\right)$ & $G_{\max }\left(\mathrm{cm}^{-1}\right)$ & $t_{G_{\max }}(\mathrm{ns})$ & $t_{F+}(\mathrm{ns})$ & $t_{\text {diff }}(\mathrm{ns})$ \\
\hline 10 & 310 & $3.0 \cdot 10^{17}$ & 0.36 & 43.5 & 39.8 & 3.7 \\
\hline 20 & 310 & $3.0 \cdot 10^{17}$ & 0.66 & 56.3 & 52.5 & 3.8 \\
\hline 22.5 & 310 & $3.0 \cdot 10^{17}$ & 0.74 & 61.5 & 57 & 4.5 \\
\hline 25 & 310 & $3.0 \cdot 10^{17}$ & 0.78 & 66 & 61.5 & 5.5 \\
\hline 27.5 & 310 & $3.0 \cdot 10^{17}$ & 0.77 & 72 & 66 & 6 \\
\hline 30 & 310 & $3.0 \cdot 10^{17}$ & 0.75 & 76.5 & 70.5 & 6 \\
\hline 40 & 310 & $3.0 \cdot 10^{17}$ & 0.66 & 96 & 87 & 9 \\
\hline
\end{tabular}

TABLE 2. Capillary parameters: $I_{\max }=50 \mathrm{kA}, r_{0}=0.6 \mathrm{~mm}$, carbon, alumina.

\begin{tabular}{cccccc}
\hline radius $(\mathrm{mm})$ & $N_{0}\left(\mathrm{~cm}^{-3}\right)$ & $G_{\max }\left(\mathrm{cm}^{-1}\right)$ & $t_{G_{\max }}(\mathrm{ns})$ & $t_{F+}(\mathrm{ns})$ & $t_{\text {diff }}(\mathrm{ns})$ \\
\hline 0.65 & $3.0 \cdot 10^{17}$ & 0.66 & 68.3 & 63 & 5.3 \\
\hline 0.6 & $3.0 \cdot 10^{17}$ & 0.78 & 66 & 61.5 & 5.5 \\
\hline 0.55 & $3.0 \cdot 10^{17}$ & 0.90 & 64.5 & 59.3 & 5.2 \\
\hline 0.5 & $3.0 \cdot 10^{17}$ & 1.04 & 63 & 57.8 & 5.2 \\
\hline 0.45 & $3.0 \cdot 10^{17}$ & 1.20 & 60.8 & 56.3 & 4.5 \\
\hline 0.4 & $3.0 \cdot 10^{17}$ & 1.35 & 59.3 & 54.8 & 4.5 \\
\hline 0.35 & $3.0 \cdot 10^{17}$ & 1.58 & 57 & 53.3 & 3.7 \\
\hline 0.3 & $3.0 \cdot 10^{17}$ & 1.66 & 54.8 & 51.8 & 3.0 \\
\hline 0.25 & $3.0 \cdot 10^{17}$ & 1.38 & 53.3 & 50.3 & 3.0 \\
\hline
\end{tabular}

TABLE 3. Capillary parameters: $I_{\max }=50 \mathrm{kA}, t_{1}=25 \mathrm{~ns}, t_{2}=310 \mathrm{~ns}$, carbon, alumina.

\begin{tabular}{ccccccc}
\hline$t_{1}(\mathrm{~ns})$ & $t_{2}(\mathrm{~ns})$ & $N_{0}\left(\mathrm{~cm}^{-3}\right)$ & $G_{\max }\left(\mathrm{cm}^{-1}\right)$ & $t_{G_{\max }}(\mathrm{ns})$ & $t_{F+}(\mathrm{ns})$ & $t_{\text {diff }}(\mathrm{ns})$ \\
\hline 15 & 30 & $1.0 \cdot 10^{17}$ & 0.09 & 46 & 39.8 & 6.2 \\
\hline 17.5 & 35 & $1.0 \cdot 10^{17}$ & 0.11 & 51 & 43.5 & 7.5 \\
\hline 20 & 40 & $1.0 \cdot 10^{17}$ & 0.26 & 54.8 & 48 & 6.8 \\
\hline 22.5 & 45 & $1.0 \cdot 10^{17}$ & 0.13 & 59.3 & 50.3 & 9 \\
\hline 25 & 50 & $1.0 \cdot 10^{17}$ & 0.12 & 63 & 54 & 9 \\
\hline 30 & 60 & $1.0 \cdot 10^{17}$ & 0.002 & 84.5 & 74.8 & 9.7 \\
\hline
\end{tabular}

TABLE 4. Capillary parameters: $I_{\max }=35 \mathrm{kA}, r_{0}=0.6 \mathrm{~mm}$, nitrogen, alumina. 


\begin{tabular}{ccccccc}
\hline$t_{1}(\mathrm{~ns})$ & $t_{2}(\mathrm{~ns})$ & $N_{0}\left(\mathrm{~cm}^{-3}\right)$ & $G_{\max }\left(\mathrm{cm}^{-1}\right)$ & $t_{G_{\max }}(\mathrm{ns})$ & $t_{F+}(\mathrm{ns})$ & $t_{\text {diff }}(\mathrm{ns})$ \\
\hline 15 & 30 & $1.0 \cdot 10^{17}$ & 0.34 & 50.3 & 44.3 & 6 \\
\hline 17.5 & 35 & $1.0 \cdot 10^{17}$ & 0.36 & 54 & 47.3 & 6.7 \\
\hline 17.5 & 35 & $1.0 \cdot 10^{17}$ & 0.08 & 50 & 43.5 & 6.5 \\
\hline 20 & 40 & $1.0 \cdot 10^{17}$ & 0.37 & 58.5 & 47.3 & 6.7 \\
\hline 20 & 40 & $1.0 \cdot 10^{17}$ & 0.16 & 54 & 47.3 & 6.7 \\
\hline 22.5 & 45 & $1.0 \cdot 10^{17}$ & 0.32 & 63 & 54.8 & 8.2 \\
\hline 22.5 & 45 & $1.0 \cdot 10^{17}$ & 0.1 & 59.3 & 49.5 & 9.8 \\
\hline 25 & 50 & $1.0 \cdot 10^{17}$ & 0.29 & 67 & 58.5 & 8.5 \\
\hline 30 & 60 & $1.0 \cdot 10^{17}$ & 0.24 & 76 & 64 & 10 \\
\hline 40 & 80 & $1.0 \cdot 10^{17}$ & 0.16 & 93 & 81 & 12 \\
\hline
\end{tabular}

TABLE 5. Capillary parameters: $I_{\max }=50 \mathrm{kA}, r_{0}=0.6 \mathrm{~mm}$, nitrogen, alumina, bornitrid.

\begin{tabular}{cccccc}
\hline radius $(\mathrm{mm})$ & $N_{0}\left(\mathrm{~cm}^{-3}\right)$ & $G_{\max }\left(\mathrm{cm}^{-1}\right)$ & $t_{G_{\max }}(\mathrm{ns})$ & $t_{F+}(\mathrm{ns})$ & $t_{\text {diff }}(\mathrm{ns})$ \\
\hline 0.6 & $0.5 \cdot 10^{17}$ & 0.29 & 56.3 & 49.5 & 6.8 \\
\hline 0.55 & $0.5 \cdot 10^{17}$ & 0.37 & 54 & 47.3 & 6.7 \\
\hline 0.5 & $0.5 \cdot 10^{17}$ & 0.46 & 52.5 & 45.8 & 6.7 \\
\hline 0.45 & $1.0 \cdot 10^{17}$ & 0.49 & 50.3 & 43.5 & 6.8 \\
\hline 0.4 & $2.0 \cdot 10^{17}$ & 0.55 & 48 & 41.3 & 6.7 \\
\hline 0.35 & $2.0 \cdot 10^{17}$ & 0.68 & 46.5 & 40.5 & 6 \\
\hline 0.3 & $5.0 \cdot 10^{17}$ & 0.86 & 45 & 39 & 6 \\
\hline 0.3 & $2.0 \cdot 10^{17}$ & 1.05 & 45 & 38.8 & 6.7 \\
\hline 0.25 & $5.0 \cdot 10^{17}$ & 1.24 & 42.8 & 37.5 & 5.3 \\
\hline 0.25 & $5.0 \cdot 10^{17}$ & 1.29 & 42 & 36.8 & 5.2 \\
\hline
\end{tabular}

TABle 6 . Capillary parameters: $I_{\max }=35 \mathrm{kA}, t_{1}=20 \mathrm{~ns}, t_{2}=40 \mathrm{~ns}$, nitrogen, alumina, bornitrid.

\begin{tabular}{cccccc}
\hline radius $(\mathrm{mm})$ & $N_{0}\left(\mathrm{~cm}^{-3}\right)$ & $G_{\max }\left(\mathrm{cm}^{-1}\right)$ & $t_{G_{\max }}(\mathrm{ns})$ & $t_{F+}(\mathrm{ns})$ & $t_{\text {diff }}(\mathrm{ns})$ \\
\hline 0.6 & $1 \cdot 10^{17}$ & 0.36 & 58.5 & 51 & 7.5 \\
\hline 0.55 & $1 \cdot 10^{17}$ & 0.44 & 56.3 & 48.8 & 7.5 \\
\hline 0.5 & $1 \cdot 10^{17}$ & 0.55 & 54 & 47.3 & 6.7 \\
\hline 0.45 & $1 \cdot 10^{17}$ & 0.66 & 51 & 45 & 6.7 \\
\hline 0.4 & $2 \cdot 10^{17}$ & 0.76 & 48.8 & 42.8 & 6 \\
\hline 0.35 & $5 \cdot 10^{17}$ & 0.98 & 45.8 & 40.5 & 5.3 \\
\hline 0.3 & $5 \cdot 10^{17}$ & 1.24 & 43.5 & 39 & 4.5 \\
\hline 0.25 & $10 \cdot 10^{17}$ & 1.54 & 41.3 & 37.5 & 3.8 \\
\hline
\end{tabular}

TABLE 7. Capillary parameters: $I_{\max }=50 \mathrm{kA}, t_{1}=20 \mathrm{~ns}, t_{2}=40 \mathrm{~ns}$, nitrogen, alumina. 

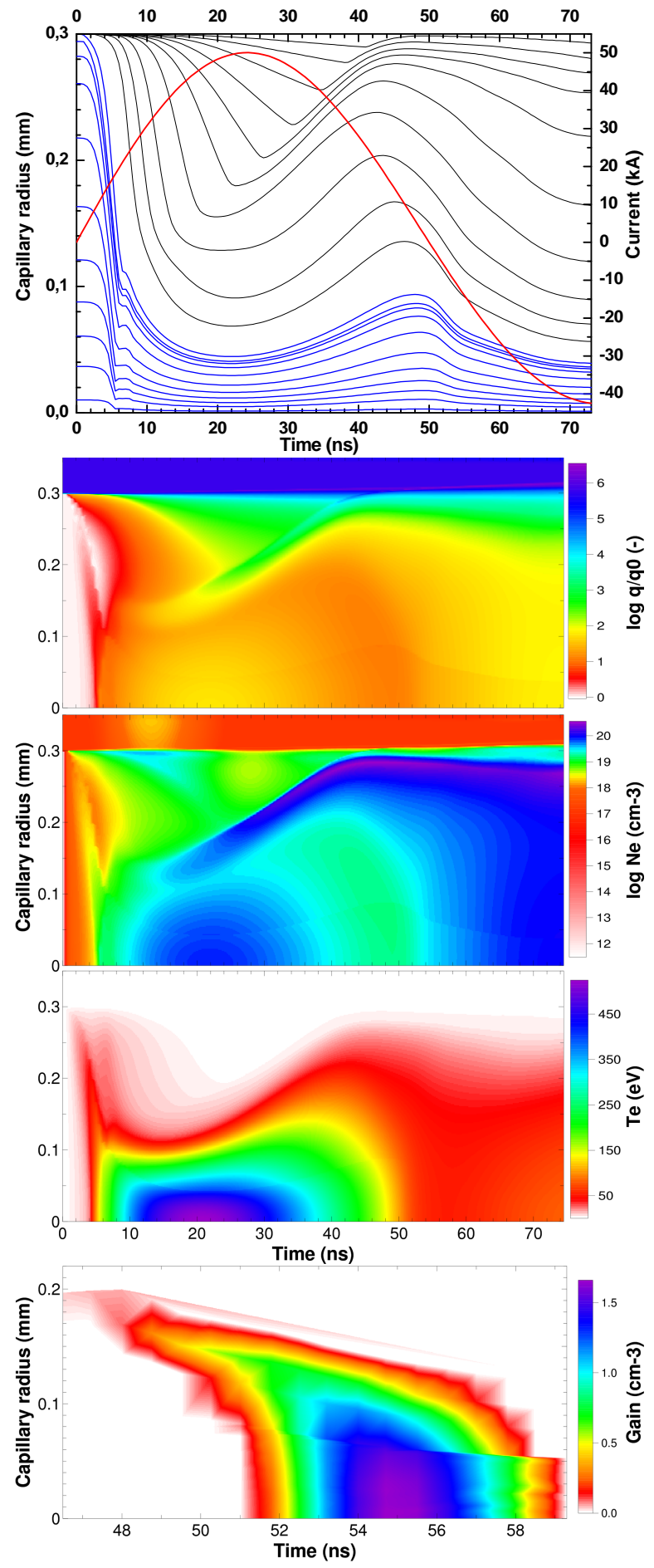

FIGURE 11. Results of computer simulations of the capillary discharge dynamics for an ablating capillary of $0.3 \mathrm{~mm}$ inner radius prefilled with carbon to an initial density $N 0=3 \cdot 10^{17} \mathrm{~cm}^{-3}$. The 1 st frame from the top shows the radial motion of the plasma mass elements. Black lines correspond to the motion of the carbon mass elements, blue lines correspond to the motion of wall ablated material (alumina), and the red line plots a current profile $\left(I_{\max }=50 \mathrm{kA}, t_{1}=25 \mathrm{~ns}\right.$, $t_{2}=310 \mathrm{~ns}$ ). The $2 \mathrm{nd}$ frame shows the mass density compression ratio in $\log _{10}$ scale. The 3 rd frame shows the electron density in $\log _{10}$ scale and units of $\mathrm{cm}^{-3}$. The 4 th frame shows the electron temperature in units of $\mathrm{eV}$. The 5 th frame shows the gain profile in units of $\mathrm{cm}^{-1}$.

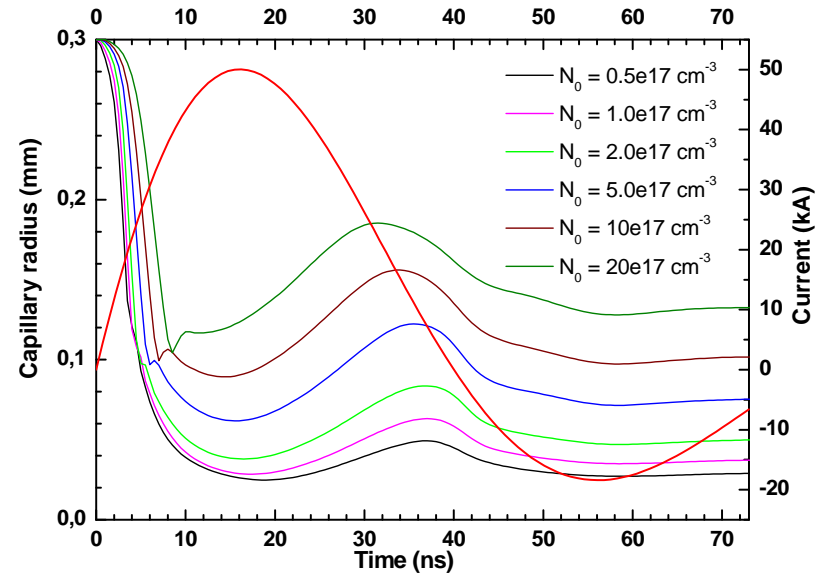

Figure 12. Motion of the border between the inner filling (nitrogen) and the wall ablated material plasma mass elements for various different initial densities in units of $\mathrm{g} / \mathrm{cm}^{3}$ in a capillary of $0.3 \mathrm{~mm}$ inner radius, the thick red line plots the current profile $\left(I_{\max }=\right.$ $\left.50 \mathrm{kA}, t_{1}=20 \mathrm{~ns}, t_{2}=40 \mathrm{~ns}\right)$.

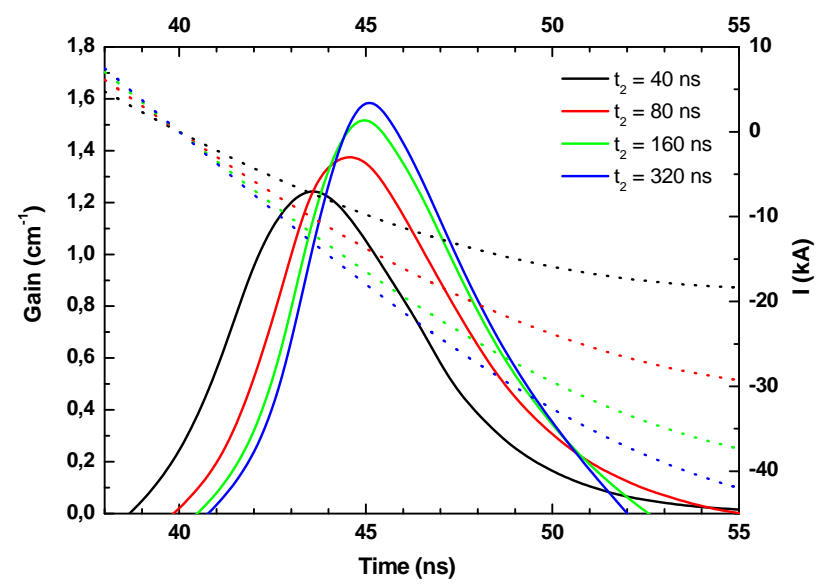

Figure 13. Gain profile (thick lines) at the axis in the unit of $\mathrm{cm}^{-1}$ for different exponential decays $\left(t_{2}=40\right.$ $320 \mathrm{~ns}$ ) at current profiles (dotted lines, $I_{\max }=50 \mathrm{kA}$, $\left.t_{1}=20 \mathrm{~ns}\right)$. The other capillary parameters were: inner radius $r_{0}=0.3 \mathrm{~mm}$, initial density $N_{0}=5$. $10^{17} \mathrm{~g} / \mathrm{cm}^{3}$, inner filling nitrogen, and alumina wall material.

\subsection{INITIAL DENSITY AND THE BORDER BETWEEN INNER AND WALL ABLATED MATERIAL}

The initial density $N_{0}$ influences not only the gain but also the sizes of the areas that belong to the inner and ablated plasma. Figure 12 shows how the boundary between these two nonmixing areas evolves. The information about the maximum gain at the $G_{\max }$ axis and the gain at the boundary line $G_{\max , b}$ for each initial density $N_{0}$ is embedded into Table 8 . The best conditions for $G_{\max }$ at the axis are reached with $N_{0}=5 \cdot 10^{17} \mathrm{~cm}^{-3}$ but if the information about the boundary is taken into account, $N_{0}=10 \cdot 10^{17} \mathrm{~cm}^{-3}$ would be better for the total gain from the whole area. 


\begin{tabular}{cccccc}
\hline$N 0\left(\mathrm{~cm}^{-3}\right)$ & Gain $_{\max }\left(\mathrm{cm}^{-1}\right)$ & $t_{G_{\max }}(\mathrm{ns})$ & $t_{F+}(\mathrm{ns})$ & $t_{\text {diff }}(\mathrm{ns})$ & $\operatorname{Gain}_{B, \max }\left(\mathrm{cm}^{-1}\right)$ \\
\hline $1 \cdot 10^{17}$ & 1.14 & 44.3 & 39 & 5.3 & 1.08 \\
\hline $2 \cdot 10^{17}$ & 1.19 & 44.3 & 39 & 5.3 & 1.08 \\
\hline $5 \cdot 10^{17}$ & 1.24 & 43.5 & 39 & 4.5 & 0.89 \\
\hline $10 \cdot 10^{17}$ & 1.18 & 42.8 & 38.3 & 4.5 & 0.52 \\
\hline $20 \cdot 10^{17}$ & 0.82 & 41.3 & 37.5 & 3.8 & 0.072 \\
\hline
\end{tabular}

TABLE 8. Capillary parameters: $I_{\max }=50 \mathrm{kA}, t_{1}=20 \mathrm{~ns}, t_{2}=40 \mathrm{~ns}, r_{0}=0.3 \mathrm{~mm}$, nitrogen, alumina.

\subsection{EXPONENTIAL DECAY PARAMETER}

The final parameter which has not been mentioned yet is time $t_{2}$ in an exponential function which affects the oversight value of the electric current, and the position of $t_{I_{\max }}\left(t_{I_{\max }}\right.$ is the time when the maximum current is reached. The smaller $t_{2}$ is, the sooner $t_{I_{\max }}$ is reached). Because the gain is situated in the third quarter period of the sinusoidal pulse, the gain is also influenced by the oversight of the current. Figure 13 shows how the gain profile changes with different decay times. This behavior can be explained exactly by shifts of $t_{I_{\max }}$ rather than by the value of the current oversight. The time $t_{I_{\max }}$ is reached slightly later with increasing $t_{2}$, so the maximum for the plasma quantities is reached slightly later. The subsequent cooling is then more rapid, which leads to better gain.

\section{DISCUSSION AND CONCLUSION}

Optimal set-ups have been sought for a nitrogen filling and for a carbon filling in the range of the selected parameters. The influence of each parameter on the gain is described in detail. Capillary radius $r_{0}$ and quarter period $t_{1}$ have the greatest impact on the gain. Hence, to achieve a sufficiently high gain $(G>1)$ it is necessary to use a very narrow capillary $\left(r_{0}=0.25-0.3 \mathrm{~mm}\right)$ and a very fast electric current $\left(t_{1}=15-30 \mathrm{~ns}\right)$. We should also point out problems that can arise. The biggest problem is the ablation process itself. The ablation subsequently damages the inner capillary wall and consequently changes the radius of the capillary from shot to shot. Repetition while conserving the initial parameters is not therefore possible for a larger amount of shots. Such narrow capillaries could even break very often. We should also mention the simplification of the plasma-wall interaction, which is considering the evaporated material from the wall as a cold neutral gas of high density and sufficiently high total mass: this simplification may not be valid for $I_{\max }<35 \mathrm{kA}$. The rate of ablation also changes with initial density. With higher initial pressures the rate is lower than for lower pressures.

\section{ACKNOWLEDGEMENTS}

This research was supported by the Czech Science Foundation Project No. GAČR P102/12/2043.

\section{REFERENCES}

[1] Rocca, J.J.: Table-top soft x-ray lasers. Review of Scientific Instruments, vol. 70, no. 10, 3799 (1999)

[2] Hosokai, T., Nakajima, M.,Aoki, T., Ogava, M., Horioka, K.: Correlation between Soft X-Ray Emission and Dynamics of Fast Capillary Discharges. Jpn. J. Appl. Phys. 36, 2327 (1997)

[3] Shin, H.-J., Kim, D.-E., Lee, T.-N.: Soft X-Ray Amplification in Capillary Discharge. Phys. Rev. E 50, 1376 (1994)

[4] Elton, R. C.: X-Ray Laser. Academic Press, New York, (1990).

[5] Razinkova, T.L., Sasarov, P.V.: Program NPINCH na počitáni dynamiky z-pinče, Moskva 1998.

[6] Vrba, P., et al.: Modeling of capillary Z-pinch recombination pumping of boron extreme ultraviolet laser. Physics of Plasmas 16, 073105 (2009)

[7] Kampel, N. S., et al.: Feasibility of a nitrogen-recombination soft-x-ray laser using capillary discharge $Z$ pinch. Phys. Rev. E 78(5), 056404 (2008)

[8] Nevrkla, M., et al.: Time-resolved XUV Radiation Diagnostics from Nitrogen Discharge Z-pinching Plasma. Proceedings of SPIE 8140, 814016 (2011)

[9] Nevrkla, M., Jancarek, A., et al.: Capillary Discharge Apparatus for Intense XUV Radiation Generation. IET Pulsed Power Conference (2009)

[10] Hubner, J.: Capillary Discharge Parameter Assessment for X-ray Laser Pumping. Acta Polytechnica Vol. 50 No. 4 (2010)

[11] Vrba, P., et al.: Analysis of Laser Pumping by Capillary Pinching Discharge in Argon and Nitrogen. Springer proceedings in Physics 115 (2007)

[12] Vrba, P., Vrbova, M.:, Optimization of Nitrogen Filled Capillary Pinch for Soft X-ray Laser Recombination Pumping. Proc. SPIE 6702, 67020W (2007)

[13] P. Vrba, M. Vrbova, N.A. Bobrova and P.V. Sasorov, Cent. Eur. J. Phys. 3, 564 (2005) 